
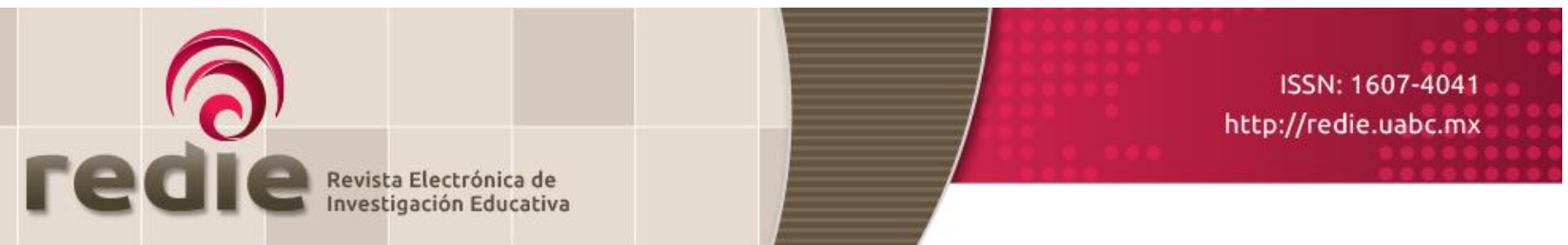

Vol. 21, 2019/e02

\title{
Políticas educacionales brasileñas: consecuencias de un currículo nacional
}

\section{Brazilian Education Policies: Consequences of a National Curriculum}

\author{
Maria de Lourdes Pinto de Almeida (1) malu04@gmail.com \\ Hildegard Susana Jung (2) hildegardsjung@gmail.com \\ Edite Maria Sudbrack (3) sudbrack@uri.edu.br \\ (1)Universidade do Oeste do Santa Catarina \\ (2) Centro Universitário La Salle \\ (3) Universidade Regional Integrada do Alto Uruguai e das Missões \\ (Recibido: 31 de mayo de 2017; Aceptado para su publicación: 20 de julio de 2017)
}

Cómo citar: Pinto, M. de L., Jung, H. S. y Sudbrack, E. M. (2019). Políticas educacionales brasileñas: consecuencias de un currículo nacional. Revista Electrónica de Investigación Educativa, 21, e02, 1-9. doi:10.24320/redie.2019.21.e02.1784

\section{Resumen}

El artículo, de investigación cualitativa y teórica, tiene como objetivo debatir las posibles consecuencias de una Base Nacional Curricular Común (BNCC) en la Educación Básica brasileña en el contexto de las políticas curriculares. La metodología para análisis de los documentos oficiales y discurso del Estado ha sido la dialéctica. La fundamentación teórica se basa en la teoría gramsciana, y se discute si la BNCC promueve la emancipación o representa un instrumento de regulación. Se han encontrado aparatos hegemónicos en la BNCC, pues la selección de contenidos denuncia la visión de un grupo respecto a lo que es legítimo enseñar, en un ejercicio de regulación. Los resultados indican que rescatar la praxis reflexiva en lugar de la cultura de la gerencia -propia de la concepción empresarial de la investigación en política educacional- parece condición fundamental para recuperar el valor e importancia de un intelectual que organice un proyecto emancipador.

Palabras clave: Política educacional, evaluación del currículum, pertinencia del plan de estudios, educación básica.

\section{Abstract}

This qualitative and theoretical study aims to discuss the possible consequences of a National Common Curriculum Basis in basic-level education in Brazil in the context of curriculum policies. Official documents and state discourse were analyzed using a dialectical methodology. Gramscian theory serves as the basis for the theoretical foundation of this work, which discusses whether the Common National Basis promotes emancipation or constitutes a regulatory instrument. Hegemonic structures were found in the Common Basis, as content selection testifies to one group's vision of what should be taught - a regulatory exercise. The results indicate that salvaging reflective praxis in place of a culture of management - typical of a business approach to research in education policy - seems fundamental in reclaiming the value and importance of intellectuals organizing emancipatory projects. 


\section{Introducción}

La formulación de una Base Nacional Curricular Común (BNCC) es idea recurrente en Brasil, en un intento por definir un currículo de carácter nacional. Este movimiento ganó fuerza con la aprobación del Plan Nacional de Educación (PNE), Ley 13005/2014 (2014). En términos más amplios, el establecimiento de una BNCc ha sido un proyecto que se desarrolla juntamente con la implementación de propuestas liberales para la educación y que busca adecuar la enseñanza a las exigencias de la administración capitalista.

Bianchetti (1996) señala dos teorías como fundamentales en las propuestas neoliberales: la primera sería la del capital humano, según la cual la función de la escuela se reduce a la formación de recursos humanos para la producción económica, en cuya lógica se tendría que articular el sistema educativo con el sistema productivo, subordinado el primero a la demanda del segundo; la otra teoría se refiere a la reducción de la política a la lógica del mercado, que premia las políticas públicas (con la moneda política corriente, el voto) o no, según su eficacia para ofrecer bienes públicos: por un lado se preocupa por organizar el aparato de producción de bienes públicos, y por otro presiona y recompensa la actuación de los agentes que producen los bienes públicos. Con ello, ocurre un fenómeno de despolitización de distintas esferas de la sociedad, incluidas la escuela y el propio Estado. Así, la reflexión sobre el tema se debe hacer a partir del análisis del escenario económico e ideológico de los tiempos de globalización.

Resultado de la investigación cualitativa y teórica, este artículo debate, en el escenario antes descrito, algunas posibles consecuencias de la implantación de una BNCC en la Educación Básica brasileña, en el contexto de las políticas curriculares y en la formación de profesores. La elección de esta metodología se debe a la intención de pensar en las contradicciones de una realidad en permanente transformación. Además, como decía Hegel, la realidad es siempre más rica de lo que se presenta; sin embargo, debe verse con la mirada cuidadosa del observador. Karl Marx con su materialismo dialéctico superó al idealista Hegel estudiando también el trabajo físico y los problemas relacionados con la alienación, entendiendo que el investigador que sigue una línea teórica basada en la dialéctica debe tener presente en su estudio una concepción dialéctica de la realidad natural y social y del pensamiento, la materialidad de los fenómenos y que es posible conocerlos (Triviños, 1987, p. 73).

Para explicitar los papeles de la educación en la sociedad liberal contemporánea se hace un recuento de las doctrinas liberales, que se presentan siempre en contraposición a las ideas intervencionistas, y admiten la necesidad de la participación activa del poder público en la definición de las metas comunes y en la corrección de los desarreglos económicos. Sin embargo, ese recorte entre "liberales" e "intervencionistas" no puede ser establecido de forma radical, pues hay que analizarlo desde matices que delimitan distintos grados de liberalismo e intervencionismo, en el sentido de determinar las competencias de los individuos, empresas y organizaciones públicas, en especial del Estado en la definición del "bien común", que puede ser concebido tanto como punto de salida para los intervencionistas, como punto de llegada para los liberales. Se señalan las características básicas de ese nuevo mercado, para el cual se exige la formación de trabajadores polivalentes y capaces de sobrevivir a la flexibilización y "precarización" del empleo. Para ello, correlacionamos elementos históricos y conceptuales para comprender el liberalismo basado en la teoría gramsciana que incorpora categorías marxianas, considerando en sus formulaciones los orígenes materiales e históricos de clase, los antagonismos presentes en la lucha de clases, así como la importancia de la lucha por la consciencia de clase en el proceso de transformación de la sociedad capitalista.

En un segundo momento, se debaten las posibles consecuencias de una BNCC -y de su proceso de implantación- para las políticas educacionales brasileñas, desde una perspectiva gramsciana. Al interior de este debate, además de la cuestión ideológica se hace un análisis tomando en cuenta las categorías Autonomía, Consenso y Emancipación, aunque la profundización se establezca en la última categoría. A partir de esta discusión surgen las preguntamos que intentamos responder en este artículo: ¿Una BNCC promueve emancipación?, ¿en verdad representa un importante instrumento de regulación?, y ¿cuáles son sus consecuencias para la formación de profesores y para la Educación Básica? 


\section{El credo liberal: un breve recorrido}

La concepción de educación liberal difiere de la propuesta educacional de los intervencionistas justamente en lo que concierne al papel del individuo ante la comunidad. En caso de la educación liberal tendría que preparar a individuos competentes para actuar políticamente en el sentido de su participación en las distintas esferas públicas y actuar, en alguna medida, en el control de las instancias económicas a partir de la reglamentación del mercado. Ese sería el principal pilar del modelo democrático intervencionista, que lo diferencia tanto del liberalismo como del modelo intervencionista centralizado o totalitario.

La retórica liberal intenta oponer las referidas tendencias económicas como extremos irreconciliables. Рara Friedman (1977, p. 21), sólo hay dos medios de coordinar las actividades económicas de millones. Uno de ellos es la dirección central utilizando la coerción -la técnica del Ejército y del Estado totalitario moderno; el otro es la cooperación voluntaria de los individuos -la técnica del mercado. Así, cualquier intento político o público, incluso democrático de control del mercado, sonaría como totalitarismo.

En la concepción liberal y neoliberal se da énfasis a los individuos como agentes racionales cuya realización de los intereses promovería el bien común. No entraremos en la discusión de lo que es el bien común; sin embargo, para un liberal coherente, será siempre resultado de la agregación de elecciones individuales y el mercado es el mecanismo natural articulador de esas elecciones. El liberal concibe el bien común como algo a posteriori. Así, la educación debe estar articulada de alguna manera con la acción individual, de modo que promueva su racionalidad, preparando a individuos aptos para actuar de forma competitiva, según el funcionamiento del propio mercado. Ante ese supuesto la educación resulta una mercancía: se trata de preparar a profesionales competitivos. La enseñanza es, a la vez, un producto del mercado y aceite que lubrica un engranaje, pues sin individuos bien preparados el mercado no funciona, son necesarios profesionales calificados para promover la producción. Sin embargo, la oferta y el empleo de la mano de obra calificada en la enseñanza se somete, asimismo, a la ley del mercado. Por eso no sorprende ver a un ingeniero desempleado vendiendo hot dogs. Ese fenómeno ha sido atribuido a las nuevas exigencias del mercado laboral, que ahora es altamente flexible.

El credo liberal se ha ido afirmando gracias a la industrialización, ante los principios de la ética paternalista católica y del mercantilismo. En ese sentido, el individualismo inherente al liberalismo clásico se convirtió en la ideología dominante del capitalismo, cuyos principios fueron el egoísmo, la frialdad calculista y el atomismo (Hunt y Sherman, 1977), movidos por los impulsos egoístas de maximizar la felicidad, es decir, disminuir el sufrimiento y aumentar los placeres. Smith (1985), el gran sistematizador del ideario liberal, decía que debemos esperar el pan no de la bondad del panadero sino de su egoísmo, pues es pensando en incrementar sus ganancias y no en hacer una buena acción que se empeña en producir sus productos.

Se predica el desarme del sistema público de previsión social y la privatización de las empresas estatales. La antigua noción de inversión pública en sectores estratégicos no tendría más sentido para los neoliberales. En lo que atañe al comercio internacional, las naciones más poderosas predican la total liberación de fronteras y tasas, aunque mantienen medidas proteccionistas que no se limitan a restricciones del dumping social, sino a una serie de cobros de tasas directas e indirectas que inciden sobre los intereses de los socios comerciales, principalmente los más débiles; Nassif (1997) ha denunciado esas prácticas sospechosas. 'Los gobiernos que más se han identificado con las prácticas neoliberales fueron los de Margaret Thatcher, en Inglaterra, y Ronald Reagan, en Estados Unidos.

En cuanto a las relaciones entre capital y trabajo el paradigma japonés de organización empresarial fue aceptado como el más estandarizado. Ese modelo permitió al capitalismo, de acuerdo con sus defensores, rebasar a las organizaciones productivas moldeadas en los principios tayloristas-fordistas para un nuevo orden fabril, donde el papel del trabajador sería mucho más inteligente y activo, es decir, menos alienado. Al respecto, Oliveira (1996) señala que para las nuevas relaciones de trabajo es necesario un trabajador capaz, cooperativo y analítico. Dicho empleado tiene que generar soluciones desde el conocimiento para mejorar los nuevos procesos de producción. Nada más en conformidad con el sistema productivo fabril comenzado por la empresa japones Toyota, en el que el trabajador asume el control de la calidad, con la

\footnotetext{
${ }^{1}$ En "O protecionismo americano" Nassif (1997) analiza las barreras no tarifarias implementadas por los estadounidenses para contener el flujo de entrada de mercancías de Brasil.
} 
autoridad de detener la producción y dar sugerencias sobre mejoras en el proceso de fabricación. En el toyotismo, las observaciones de los obreros son estudiadas y eventualmente implementadas. Se trata de un nuevo perfil de obrero, del que se exige flexibilidad y capacidad multifuncional.

Según Oliveira (1996), los profesores no deberían ser perjudicados por las nuevas posibilidades para una renovación del proyecto pedagógico. El nuevo paradigma permitiría incorporar las concepciones de Piaget y Vygotsky con la teoría de las múltiples inteligencias, así como con la teoría de la inteligencia emocional de Goleman. Históricamente la hegemonía del nuevo modelo estaría en conformidad con el paso de una sociedad que exigía una formación masificada adaptable al modelo productivo vigente, que demanda a una multitud de trabajadores que ejecuten tareas rutinarias sin cuestionarlas. Ahora se valora al trabajador polivalente, capaz de actuar en equipo (en red), disponible para actuar en distintos sectores, incluso para viajar o trabajar conectado a una red; es decir, se prepara a un trabajador no para obedecer y actuar según las "órdenes", sino para que sepa cómo lidiar con lo imprevisible y se adapte a nuevas situaciones, para innovar. Así, parece que la conciencia de clase se volvió conciencia de equipo.

Рara Gramsci (1999), la Educación debe representar la praxis reflexiva posibilitadora de socialización del conocimiento y de la participación democrática; es decir, de "nociones concretas" de elaboración intelectual de los alumnos, profesores y de la comunidad. No se trata sólo de una nueva escuela, sino de "otra", con una significación que trasciende la gestión neoliberal y, por tanto, para la vida, para la realidad histórica de este presente. Recurrimos a los supuestos gramscianos, pues parece condición importante para que el proceso educacional esté orgánicamente relacionado con la historia contemporánea.

\section{Implementar la BNCC: un debate más allá de la regulación de la educación}

La discusión sobre los contenidos que deberían componer el currículo de la escuela popular brasileña se acentuó en la segunda mitad del siglo XIX y, de acuerdo con Souza (2000), esta temática ya traía consigo la idea de universalización. Aun así, distintos intereses tensaban las negociaciones. Internacionalmente circulaba la idea de que la escuela podría generar progreso, cambio social y modernización, y los congresos, libros y artículos diseminaban estos modelos. En este contexto de final de siglo XIX, según explica Petitat (1994), la mayoría de los países, principalmente los más desarrollados y en vías desarrollo, masificaban la escolarización, con varios aspectos en común: la obligatoriedad, la educación como responsabilidad del Estado, la secularización de la enseñanza y la secularización de la moral, la nación y la patria como principios orientadores de la cultura escolar, la educación popular concebida como un proyecto de integración ideológica y política (Souza, 2000, p. 11) y una homogeneidad en los currículos.

En Brasil, el debate alrededor de una BNCC se ha dado durante de 2015 y 2016. La razón de retomar el tema obedece a que el PNE, Ley 13.005 (2014) contempla como estrategia 2 de la meta 2 un pacto entre los gobiernos federal, provinciales y municipales con el fin de implantar objetivos que configurarán la BNCC de la enseñanza fundamental. El tema vuelve a discusión también porque desde la promulgación de la Ley de Directrices y Bases (LDB) no. 9.394 (1996) la creación de una BNCC es "plato del día" en las articulaciones políticas relacionadas con la educación.

Según Macedo (2014), antes de la promulgación de la nueva LDB (en 1996), ya se había creado el Consejo Nacional de Educación (CNE) en Brasil, atribuyéndole la deliberación sobre las directrices curriculares que proponía el Ministerio de la Educación (MEC). De esta manera, el Ministerio y el Consejo, tras consulta a la comunidad académica², a finales de 1996 se presentaron los Parámetros Curriculares Nacionales (PCN). Como no era posible ignorar las duras críticas a los PCN, se decidió entonces elaborar directrices curriculares más generales y mantener los PCN como alternativa curricular no obligatoria (Macedo, 2014, p. 1533). Y así está la situación en Brasil hasta la fecha, discutiendo esta BNcc "más general".

Alves (2014) cuestiona qué es de veras una BNCc y en la pregunta plantea la cuestión ideológica, que va mucho más allá del establecimiento de contenidos considerados esenciales o "más importantes" para el aprendizaje de los niños.

\footnotetext{
${ }^{2}$ La consulta fue realizada a individuos pero no se hizo pública, las respuestas no se informaron ni a los académicos consultados ni a los encuestados.
} 
En este mismo sentido va la campaña "Aquí ya hay currículo: el que creamos en la escuela..." ${ }^{3}$, de la Asociación Nacional de Investigadores en Educación (Anped, por sus siglas en portugués). El movimiento tiene el objetivo de dar voz a los docentes que vivencian, en la pluralidad de la escuela, distintos tipos de currículos. Рara ello, invita a enviar videos, exposiciones o textos, con el objetivo de llevar esas experiencias al CNE.

Respecto al cuestionamiento de si tiene sentido la idea de un currículo nacional, Apple (1994) reitera el carácter ideológico del documento, puesto que la selección de determinados contenidos en detrimento de otros denuncia la visión de mundo de algún segmento de la sociedad sobre lo que, en su visión, debe ser enseñado. El autor señala que él es parte de una tradición selectiva, resultado de la selección de alguien, de la visión de algún grupo acerca de lo que sea conocimiento legítimo: es producto de tensiones, conflictos y concesiones culturales, políticas y económicas (Apple, 1994, p. 59) que acomodan y desacomodan a un pueblo. Así, el proceso de selección que prioriza algunos saberes refleja la dominación y subordinación de un grupo marginado a una elite privilegiada.

La cuestión ideológica acompaña no sólo la concepción de currículo, sino la educación y sus políticas de una manera general, desde el Brasil Imperial. Los fenómenos históricos nos auxilian a entender con claridad entre líneas, como en el caso de la Ley del Vientre Libre, Ley n. 2040 (1871). Según Bonato, Coelho y Menezes (2011), en 1879 los niños nacidos libres, hijos de esclavas, completarían ocho años. El hecho generaría un problema al Estado Imperial: ¿dónde ubicar a esta población libre, en un país que quería ser considerado moderno y civilizado? Como el gobierno no tenía (y tampoco pretendía tener) una estructura que pudiera acogerlos, las propuestas de instrucción y constitución de asociaciones con particulares para ofrecer educación de tiempo integral estaban bien vistas (Fonseca, 2002). Las políticas públicas educacionales, por tanto, normalmente se revisten de una intencionalidad ideológica, y con la primera propuesta de educación de tiempo integral en Brasil no fue diferente.

La constatación de que la composición de la BNCC está tomada de componentes ideológicos -como en gran medida lo están las políticas educacionales brasileñas, independientemente del período histórico-, lleva a la concepción de hegemonía referida por Gramsci (1999), quien señaló que la práctica normal de la hegemonía está relacionada con el ejercicio combinado de la fuerza y del consenso, siendo aquélla más blanda, de manera que equilibra la opinión pública. De esta forma, contrario a lo que pueda parecer, la lucha de clases no siempre es explícita o abiertamente violenta, esa lucha ocurre de manera clandestina, como apunta Dias (2014, p. 27-28):

Es la forma por la cual hábitos, saberes y costumbres de los dominantes asumen el carácter de horizonte ideológico. [...] El dominio de una clase (y de su bloque de poder) determina qué pensar y qué estudiar e incluso qué y cómo amar.

Gramsci decía que la hegemonía de un grupo se consolida cuando éste persuade a todos los demás grupos a que acepten sus valores morales, políticos y culturales (Joll, 1977). Es decir, cuando su verdad se transformó en consenso. Ahora bien, lo que vemos es un movimiento cada vez menor de resistencia a la nueva BNCC. La hegemonía se consolida cuando hay consenso y, a la vez, el disenso alrededor de una nueva BNCC se hace cada día menor. Este proceso es fácilmente identificado en la campaña Movimiento por la Base. ${ }^{4}$ El portal muestra el histórico del movimiento -existente desde abril de $2013-$ y su propuesta, que defiende la BNCc como un eje central para los derechos de aprendizaje de cada alumno, la formación de profesores, recursos didácticos y evaluaciones externas.

Teniendo en cuenta los elementos ideológicos, hegemónicos, de poco disenso y creciente consenso en las políticas educacionales, incluyendo las curriculares y la nueva BNCC, cabe preguntarse cuál es el impacto de estas políticas y, principalmente, de la nueva BNCC en la formación de profesores y la Educación Básica brasileña; representan oportunidad de emancipación o manipulan la educación de forma que la somete aún más a la regulación de la "Patria Panóptica"5 (Jung y Sudbrack, 2016).

\footnotetext{
${ }^{3}$ http://www.anped.org.br/campanha/curriculo

${ }^{4}$ http://movimentopelabase.org.br/

${ }^{5}$ El término panóptico, recuperado de Bauman (2001), quien lo tomó prestado de Foucault, sirve como metáfora para el poder de la modernidad, que está siempre vigilando a través de las políticas de regulación. Siguiendo con la metáfora, el mismo sistema aplica sanciones a los que eventualmente no obedecen las órdenes.
} 
Gramsci tenía una especial preocupación con la escuela. Según Roio (2014), para Gramsci la escuela es entonces un elemento importante en la constitución del conformismo social, de la hegemonía de una clase sobre otra o, más explícitamente, de la dominación política y económica. De esta manera, nos sumamos a la pregunta de Alves (2014): ¿Qué es una BNCC? ¿Necesitamos una? Reconociendo la dificultad para definir lo que sería hoy una BNCC, Alves aclara que cuestionar esta base se relaciona con distintos aspectos: a) existe, internacionalmente, una idea de que podría haber un currículo nacional estandarizado para varios países -lejos de disenso o consenso, nos parece que hay una divergencia: ¿cómo puede un currículo ser nacional si la pretensión es uniformarlo en distintos países? Tal vez evaluaciones externas en gran escala, como el de PISA, tengan alguna relación con eso; b) la persistente ideología de Comenius, de una enseñanza igual para todos -leer, escribir y contar- (Alves, 2014); c) la universalización trajo para las escuelas las minorías diferentes, a las cuales los gobiernos tienen dificultades de atender, y no hubo éxito en la preparación de profesores para actuar en este nuevo ambiente.

Hay, asimismo una enorme máquina internacional de productos educativos, como bases nacionales, exámenes, folios, etc. (Alves, 2014) al servicio, también, de la lógica de la Calidad Total (TQM, por sus siglas en inglés). En Brasil, Macedo (2014) identificó a los socios de los agentes públicos que trabajan por la BNCC: grandes empresas que aplican en sus fundaciones recursos que serían utilizados para el pago de impuestos, produciendo materiales educacionales, entre ellas Itaú (Unibanco), Bradesco, Santander, Gerdau, Natura, Volkswagen, Fundação Victor Civita, Fundação Roberto Marinho, Fundação Lemann, CENPEC, Todos pela Educação y Amigos da Escola, y otras (p. 1540). Sin embargo, la constitución de una BNCC ancla su justificación en una educación de calidad, capaz de amenizar las desigualdades educacionales. La cuestión de la cualidad, por tanto, y la supuesta crisis del sistema es una de las múltiples demandas a las que responde la defensa de una BNCC relacionada con las tendencias curriculares de un mundo globalizado que, por preceptos neoliberales, pasó a tratar la educación con la lógica del mercado. ${ }^{6}$

Según Macedo (2014), las grandes corporaciones ligadas al MEC vinculan la calidad de la educación con la centralización de un currículo común, de manera que se sienten a gusto, incluso, para crear formas de gobernabilidad, como un tipo de desestatización de la educación. La educación pasa a una lógica edubusiness, cuyas consecuencias para los profesores son la responsabilización, presión por resultados y, en caso de que no se cumplan las metas, hay penalización. Así, el control -panóptico- sobre la acción pedagógica es total.

Los reflejos de la BNCC para la formación de profesores y para la Educación Básica de una manera general, por tanto, resultan ampliamente reguladores. En este sentido, Gramsci (1999) se preguntaba cómo transformar el mundo y alcanzar la emancipación; el punto de salida, sugirió, es la superación de la cultura burguesa y promoción de un significativo progreso intelectual. Este proceso se dará por medio de la educación como instrumento de lucha y de desarrollo social y humano (Roio, 2014).

\section{Consideraciones (nada) finales}

La interacción de la educación con el mercado es compleja y su comprensión exige una reflexión con varias perspectivas. Ante la noción de que el mercado es el único soberano, como creen los liberales y según proponen las directrices políticas brasileñas recientes, la educación ha sido vista como un elemento del engranaje del mercado al preparar individuos para que actúen según su racionalidad, así como al volverse ella misma una mercancía. Con eso, la tendencia de las políticas liberales es suprimir la educación como bien público, volviéndola un nudo más en la "red" denominada mercado. Sin embargo, para Gramsci (1999) la educación se debe comprometer con el conocimiento más allá de la información, como práctica consciente que alude a la participación de alumnos, maestros y gestores. Ello implica unir educación y vida para una auténtica pedagogía de la promoción humana, una pedagogía claramente emancipadora en la que el nexo instrucción-educación sea el trabajo de los sujetos de una institución educativa. En la acepción gramsciana la articulación de propuestas colectivas parece convertir el espacio escolar en el lugar donde los alumnos no ignoran las nociones concretas del conocimiento, y tampoco se detienen en fórmulas y palabras vacías y pronto olvidadas. Justo lo contrario es lo que propone la BNCC.

\footnotetext{
${ }^{6}$ TQM "supone nociones de mejor precio, ausencia de defectos, obediencia al proyecto, adecuación al uso y satisfacción del cliente por medio de mejora continua en los productos y servicios ofrecidos" (Turchi, 1997, p. 16).
} 
Aún quedaría una esperanza. Quizás el movimiento de discusión y reflexión sobre la BNcc podría suscitar lo que Gramsci denominó "catarse". Saviani (1993, p. 10) explica este término como la superación del sentido común por la conciencia filosófica, ocurriendo "el pasaje de una concepción fragmentaria, incoherente, desarticulada, implícita, degradada, mecánica, pasiva y simplista a una concepción unitaria, coherente, articulada, explícita, original, intencional, activa y cultivada". Pero la posición del autor se formula dentro de otra corriente hegemónica, opuesta al liberalismo.

Como consideraciones no tan finales - puesto que el debate recién comienza-, podemos decir que la propuesta actual de una BNCC va al encuentro de los principios metodológicos e ideológicos inherentes a la actual hegemonía liberal, cuya supremacía ha sido impuesta a todos los sectores de las sociedades mundiales. Resta saber hasta qué punto esa propuesta ofrecería elementos que podrían rescatar un análisis crítico, volviéndolos instrumentos para una perspectiva coherente con los anhelos de los oprimidos y excluidos, no en sentido de integración en un sistema excluyente por naturaleza, sino según las posibilidades de transformarlo radicalmente. Para ello estudios futuros -quizás de corte empíricopodrán ser útiles.

Lo que sí podemos concluir es que rescatar la praxis reflexiva en lugar de reforzar la cultura de la gerencia, propia de la concepción empresarial de la investigación en política educacional parece condición fundamental para recuperar el valor y la importancia del intelectual con capacidad de organicidad a un proyecto político-pedagógico emancipador. Así, de acuerdo con Gramsci, podemos decir que "el modo de ser del nuevo intelectual no sólo puede consistir en la elocuencia [...], sino en inmiscuirse activamente [...] como constructor, organizador (Gramsci, 1999, p. 11).

Sin embargo, la sociedad contemporánea presenta cambios preocupantes. La desagregación de los valores éticos y políticos individualizan la búsqueda de alternativas, pues el éxito o fracaso pasa a ser una responsabilidad individual. Más valen los intereses personales e inmediatos de los individuos que los principios para la vida colectiva. La sociedad del "sálvese quien pueda", expone su fragilidad y dificulta acciones consensuales democráticas y participativas acentuadamente. Para Marx sólo la lucha de clase revela la existencia de ese movimiento. Es ella la que permite el cambio de las condiciones materiales, modificando y creando nuevas relaciones sociales. El proceso de lucha se da en el ámbito de la organización social de la producción capitalista, pues es en ese momento que se contraponen dominantes y dominados. Las clases dominantes monopolizan la ciencia, el arte y la dimensión más ampliada de la cultura. La ciencia pasa a ser un instrumento de apropiación cultural y espiritual en las manos de la clase dominante que la usará como medio de extorsión del plusvalor.

El conocimiento se presenta como una herramienta de múltiples usos políticos, tiene tanto carácter político estratégico como libertario y de mercancía en el sentido de hacer valer los intereses económicos de los capitalistas. El poder emancipador, en su capacidad de incrementar el diálogo y las posibilidades de acción de la colectividad, pasaría por la idea de que al tiempo que la ciencia debe romper con el sentido común para desenvolverse analítica y formalmente, necesita también volver al sentido común como disponibilidad y accesibilidad, aunque su registro formal debe ser traducido a un lenguaje más funcional. Sin embargo, hay quienes piensan que al servir a los intereses inmediatos de los dominantes, la Educación propendería -a mediano o largo plazo, o indirectamente- a favorecer a toda la comunidad, pues el desarrollo social en sus diferentes aspectos incrementaría de las privatizaciones. Esa visión conlleva el prejuicio de que sólo la Escuela Privada sería una instancia de auto-organización, capaz de agenciar saber y promover beneficios comunes. Así, la distinción entre público y privado sería meramente formal pues, en la práctica, el agente del bien público podría traer beneficios inmediatos en términos de mejora del nivel de vida y ventajas financieras para los participantes.

Gramsci (1999) indica que la organicidad de pensamiento no puede ser adquirida espontáneamente en una sociedad de oprimidos y opresores. Esa idea del "práctico" generó una crisis del papel del intelectual, perpetuando el vacío y disolución de sentido en el papel del sujeto colectivo. Por otro lado, se pierde la capacidad de comprender la realidad. Aquí no se trata de que no se debe pensar y reflexionar sobre modos de transformar la realidad sino de dónde sale la función transformadora de comprenderla, qué hace que un intelectual comprenda la realidad.

A partir de las reflexiones marxistas, Gramsci (1999) destacaba la importancia del intelectual orgánico ante el intelectual tradicional en el contexto del siglo XX, etapa en la que era importante superar la idea de un intelectual elitista que se consideraba como una clase independiente, escondido detrás de una 
neutralidad científica y ajeno a las contradicciones de su tiempo. El intelectual orgánico está impelido a definirse y tomar parte en los conflictos de la historia.

Al proponer la fragmentación y el pluralismo de los saberes, los fundamentos científicos, metodológicos, filosóficos y pedagógicos de la propuesta presentada por el Estado -aunque importantes en el cuestionamiento de la tradicional forma de integración de las asignaturas y el rescate de temas como la ética y la justicia- convierte a la escuela en un escenario mediático más, con fuerte alusión a las estrategias televisivas de entretenimiento, donde hablan los no especialistas. La crisis de las ciencias y de las especialidades, como síntoma de la superación del positivismo es una buena señal, pero la sustitución de la organización del currículo tradicional por saberes no científicos es cuestionable, pues podría abrir la posibilidad de que la escuela se volviese un lugar en el que los prejuicios y la superficialidad en el tratamiento de temas relevantes tomanuna dimensión temeraria.

\section{Referencias}

Alves, N. (2014). Sobre a possibilidade e a necessidade curricular de uma base nacional comum [Sobre la posibilidad de uma base nacional común]. Revista Científica e-Curriculum, 12(3), 1464-1479.

Apple, M. W. (1994). A política do conhecimento oficial: faz sentido a ideia de um currículo nacional? Currículo, cultura e sociedade [La política del conocimiento oficial: ¿tiene sentido la idea de un currículo nacional?]. São Paulo: Cortez.

Bianchetti, R. (1996). Modelo neoliberal e políticas educacionais [Modelo neoliberal y políticas educacionales]. São Paulo: Cortez.

Bauman, Z. (2001). Modernidade líquida [Modernidad líquida]. Río de Janeiro: Jorge Zahar.

Bonato, N. M. C, Coelho, M. C. C y Menezes, J. S. S. (2011). Educação Integral, ensino integral e tem po no pensamento de Rui Barbosa [Educación Integral, enseñanza integral y tiempo en el pensamiento de Rui Barbosa]. Revista HISTEDBR On-line, 44, 275-292.

Coutinho, C. N. (1999). Gramsci, estudo sobre seu pensamento político [Gramsci, estudio sobre su pensamiento político]. Brasil: Civilização Brasileira.

Dias, E. F. (2014). Notas sobre hegemonia. En A. Schlesener (Org.) Filosofia, Política e Educação: leituras de Antônio Gramsci [Filosofía, política y educación: lecturas de Antonio Gramsci]. Brasil: UTP.

Fonseca, M. V. (2002). A educação dos negros: uma nova face do processo de abolição da escravidão no Brasil. [La educación de los negros: una nueva cara del proceso de abolición de la esclavitud en Brasil]. Brasil: EDUSF.

Friedman, M. (1977). Capitalismo e liberdade [Capitalismo y libertad]. Brasil: Arte Nova.

Gramsci, A. (1999). Cuadernos de la cárcel (A. M. Palos, Trad.). México: Era/Benemérita Universidad Autónoma de Puebla.

Hunt, E. y Sherman, H. (1977). História do pensamento econômico [Historia del pensamiento económico]. Brasil: Vozes.

Joll, J. (1977). As ideias de Gramsci [Las ideas de Gramsci]. Brasil: Cultrix.

Jung, H. S. y Sudbrack, E. M. (2016). Pátria educadora ou pátria panóptica? [Patria educadora o Patria panóptica?]. Revista Cocar, 10(19), 265-286.

Ley n. 2040. Lei do ventre livre [Ley del vientre libre] (20 de septiembre de 1871). Río de Janeiro, Brasil. Recuperado el de http://www.planalto.gov.br/ccivil 03/leis/lim/LIM2040.htm

Ley n. 9.394. Estabelece as diretrizes e bases da educação nacional [Ley que establece las directrices y bases de la educación nacional (20 de diciembre de 1996). Recuperado de

www.planalto.gov.br/ccivil 03/LEIS/l9394.htm 
Ley n. 13.005. Aprova o Plano Nacional de Educação-PNE e dá outras providências [Aprueba el Plan Nacional de Educación-PNE y otras medidas] (25 de junio de 2014).

Macedo, E. (2014). Base Nacional Curricular Comum: novas formas de sociabilidade produzindo sentidos para educação [Base Nacional Curricular Común: nuevas formas de sociabilidad produciendo sentidos para educación]. Revista Científica e-Curriculum, 12(3), 1530-1555.

Manacorda, M. A. (1999). O princípio educativo em Gramsci [El principio educativo en Gramsci](W. Lagos, Trad.). Brasil: Artes médicas.

Nassif, L. (1997). O protecionismo americano. [El proteccionismo americano]. Recuperado de https://jornalggn.com.br/economia/o-protecionismo-americano/

Oliveira, V. B. (Org.) (1996). Informática em Psicopedagogia [Informática en Psicopedagogía]. Brasil: SENAC.

Petitat, A. (1994). A produção da escola, produção da sociedade: análise sócio-histórica de alguns momentos decisivos da evolução escolar no Ocidente [La producción de la escuela, producción de la sociedad: análisis sociohistórico de algunos momentos decisivos de la evolución escolar en el Occidente]. Brasil: Artes Médicas.

Roio, M. (2014). A educação como forma de reprodução da hegemonia e seu avesso [La educación como forma de reproducción de la hegemonía y su revés]. En A. Schlesener (Org.), Filosofia, Política e Educação: leituras de Antônio Gramsci. Brasil: UTP.

Saviani, D. (1993). Educação e questões da atualidade [Educación y cuestiones de la actualidad]. Brasil: Cortez.

Smith, A. (1985). A riqueza das nações [La riqueza de las naciones]. Brasil: Nova Cultural.

Souza, R. F. (2000). Inovação educacional no século XIX: a construção do currículo da escola primária no Brasil [Innovación educacional en el siglo XIX: la construcción del currículo de la escuela primaria en Brasil]. Cadernos Cedes, 20(51).

Triviños, A. N. S. (1987). Introdução à pesquisa em Ciências Sociais: a pesquisa qualitativa em Educação. [Introducción a la investigación en Ciencias Sociales: la investigación cualitativa en Educación]. Brasil: Atlas.

Turchi, L. M. (1997). Qualidade total: afinal, de que estamos falando? [Calidad total: a fin de cuentas, ¿de qué estamos hablando?] Documento para discusión número 459. IPE, Ministério do Planejamento e Orçamento. Brasilia. 